\title{
Characteristics Analysis of Short Flux Path Switched Reluctance Motor
}

\begin{abstract}
Jin-Woo Ahn*
Abstract - A novel kind of switched reluctance motor (SRM) with short flux path is proposed in this paper. Phase excitation in the SRM gives short flux paths, hence reducing the magnetomotive force required to drive the machine, resulting in significant reduction of copper wire and core losses compared to the typical SRM with diametric circulation of magnetic flux. To verify the performance, the characteristics analysis of a double-stator SRM, a 6/5 SRM with C-core structure, and a 4/5 two-phase SRM, which all have short flux paths, and a comparison with conventional SR motors are executed. The comparison demonstrates that the proposed motor offers some advantages in terms of torque and efficiency.
\end{abstract}

Keywords: Switched Reluctance Motor, Short Flux Path, Characteristics Analysis

\section{Introduction}

The switched reluctance motor (SRM) has been widely used in many industrial applications such as aerospace, automotive, and domestic appliance manufacturing. The SRM is a novel synchronous machine that is a doubly-salient machine as both the stator and the rotor have salient poles. The stator includes the concentrated winding, whereas the rotor has no windings. Therefore, the structure is simple and the operation is reliable. The unique advantages of the SRM, which make the SRM an attractive electric motor [1], are: 1) high torque output, wide range of operating speed, simple structure and fault tolerance; 2) because of the higher self-inductance, the starting torque of the SRM can be very high without the problem of excessive inrush current, and 3) the SRM can achieve extremely high speeds with a wide constant power region and independent stator phases, which allow for continued drive operation in the case of loss of one or more phases.

A novel construction of a short flux path is proposed in order to improve the performance and reduce the losses. The basic principle of a short-flux-path machine is that it uses a short magnetic path, and the magnetic flux can flow faster than in the long-magnetic-path motors. Fig. 1 shows the basic structure of the

\footnotetext{
* Dept. of Mechatronics Engineering, Kyungsung University, Busan, Korea. (jwahn@ks.ac.kr)

Received 01 September 2011 ; Accepted 01 May 2012
}

short-flux-path type.

The electromagnetic operation for this type of SRM is different from that of the conventional SRM. Magnetic flux travels in a short flux loop in contrast to the conventional SRM, which uses a long flux path. When a stator pole is excited, the adjacent rotor pole pair is attracted towards the excited stator pole, and alignment will be achieved between stator and rotor poles. This is due to the nature of the reluctance path. The advantage of using a short flux path is to reduce the eccentric forces between the stator and rotor poles. In addition, core losses are significantly reduced due to the short distances of the travelling magnetic fields in the short flux path design. As a result, the efficiency of the SRM can be improved.

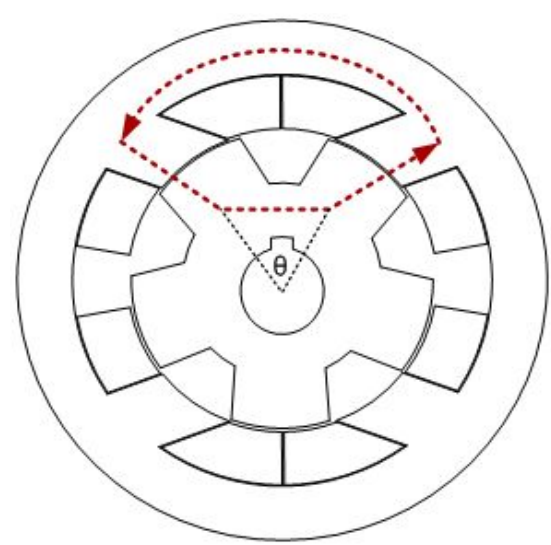

Fig. 1. Short flux path of SRM 


\section{Concept of the double-stator SRM with short flux path}

A novel double-stator SRM with short flux path, which has smaller size and higher output torque, is proposed in this paper.

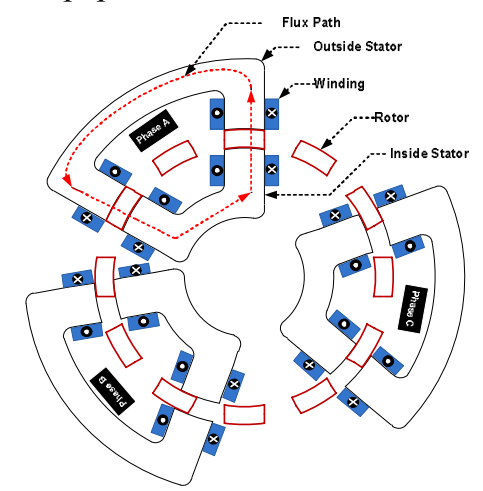

Fig. 2. Cross-section of double-stator SRM

The two stators of the SRM are independent and they are placed inside and outside of the rotor. Fig. 2 shows the cross-section of the double-stator SRM with short flux path.

There is no brush or magnet in the double-stator SRM. The rotor structure employs a yokeless rotor with no connection. The rotor consists of 12 independent rotor bars with non-electrical material used to join them. The proposed rotor employs thick independent rotor poles. The stator structure is divided into three independent stator groups. Each stator group consists of a pair of two connected poles. Fig. 3 shows the structure of the double-stator SRM.

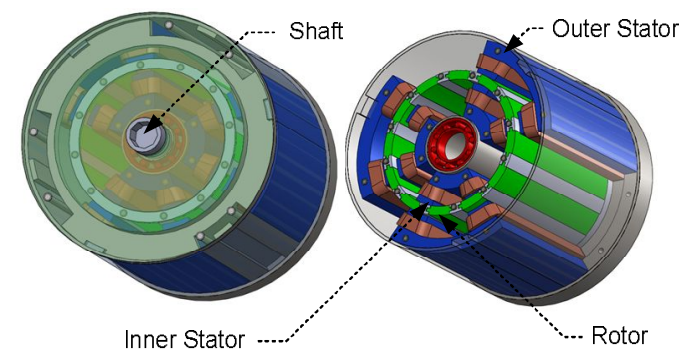

Fig. 3. Structure of double-stator SRM

\section{Concept of the 6/5 SRM with short flux path}

In order to verify the novel idea of short flux path, a novel three-phase 6/5 SRM with C-core and a two-phase SRM are designed and analyzed. Because the magnetic path is related to the core loss of a motor, the short magnetic path is better than the long one for reducing losses. The novel 6/5 SRM with short flux path has 6 stator poles, which are constructed with three physically independent $\mathrm{C}$-cores, and the rotor is composed of 5 poles. The short-flux-path motor uses a new structure in which the stators are not centralized to the origin. The three C-cores are separated by $120^{\circ}$ and the rotors are separated by $72^{\circ}$.

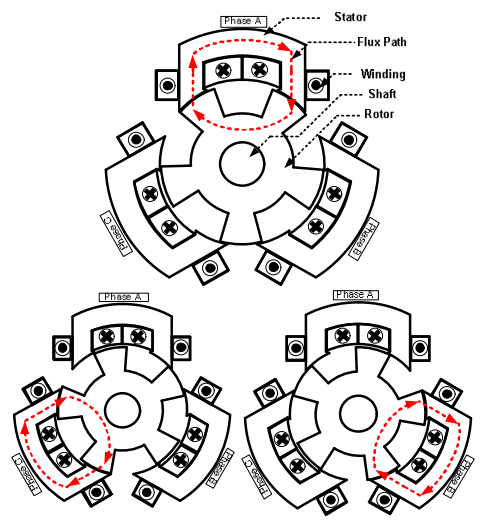

Fig. 4. Magnetic path of each phase

The windings are concentrated wound on the stator. The odd number of rotor poles is used to deliver the magnetic flux from one stator pole to another. The magnetic path of each phase is shown as Fig. 4 [2].

The amount of material and the core losses in the motor are substantially reduced because of the special structure, in which there is no connection between the C-cores, and the flux-linkage does not go through the diameter of the motor, so that a short flux path is achieved in the motor. A comparison of the flux paths between a conventional $6 / 4$ and the proposed $6 / 5 \mathrm{SR}$ motor is shown in Fig. 5.

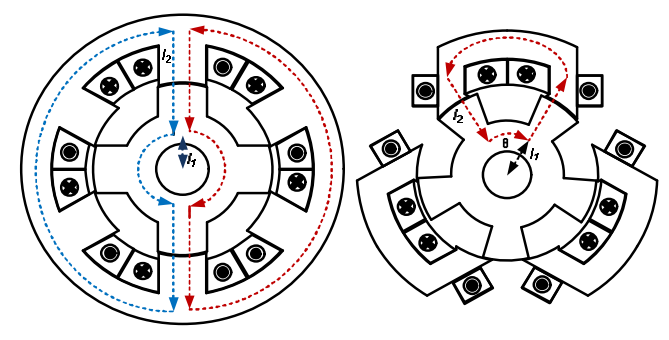

(a)

(b)

Fig. 5. Flux path (a) conventional 6/4 SRM (b) proposed 6/5 SRM

The stack lengths $1_{6 / 5}$ and $1_{6 / 4}$ in the $6 / 5$ and $6 / 4$ machines, respectively, are equal. The mean-flux-path length in the proposed 6/5 SRM is:

$$
l_{6 / 5}=2 l_{2}+\theta l_{1}+\theta\left(l_{1}+l_{2}\right)
$$

The mean-flux-path length in the conventional $6 / 4$ $\mathrm{SRM}$ is:

$$
l_{6 / 4}=2 l_{2}+\pi l_{1}+\pi\left(l_{1}+l_{2}\right)
$$

The ratio of the lengths of the mean flux paths of the two SRMs is: 


$$
\frac{l_{6 / 5}}{l_{6 / 4}}=\frac{2 l_{2}+\theta\left(2 l_{1}+l_{2}\right)}{2 l_{2}+\pi\left(2 . l_{1}+l_{2}\right)}
$$

The arc $\theta$ subtended by the mean flux path in the $6 / 5$ SRM is:

$$
\theta=\frac{360^{\circ}}{5}=72^{0}
$$

The ratio of the mean flux paths in the two SRMs can be evaluated and given as:

$$
\frac{l_{6 / 5}}{l_{6 / 4}} \approx 0.4
$$

From (5), it can be seen that the 6/5 C-core SRM only utilizes $40 \%$ of the core material compared to its counterpart, the conventional 6/4 SRM. This leads to significant savings in the iron-core material required to drive the SRM, and will also significantly improve the efficiency of the motor [3].

\section{Concept of the 4/5 SRM}

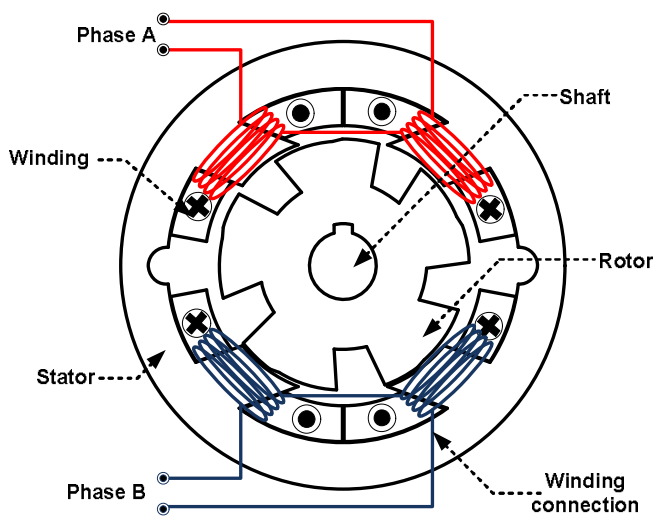

Fig. 6. 4/5 SRM structure with short flux path

In order to further study the short flux path, a novel 4/5 SRM was designed and analyzed. The two-phase 4/5 SRM has four stator and five rotor poles, and employs a short flux path instead of the long flux path found in conventional SRMs. The novel 4/5 SRM structure with short flux path is shown in Fig. 6 .

To improve the efficiency and torque, decreasing the core losses is important. The short-flux-path motor needs lower MMF to produce the same output torque as compared to the conventional long-magnetic-path motor. Furthermore, with a shorter flux path, the current required and the number of winding turns in the motor can be reduced. A short magnetic flux path requires the flux to flow between two adjacent poles in a phase, from one pole to the other. The proposed magnetic flux paths are shown in Fig. 7 [4].

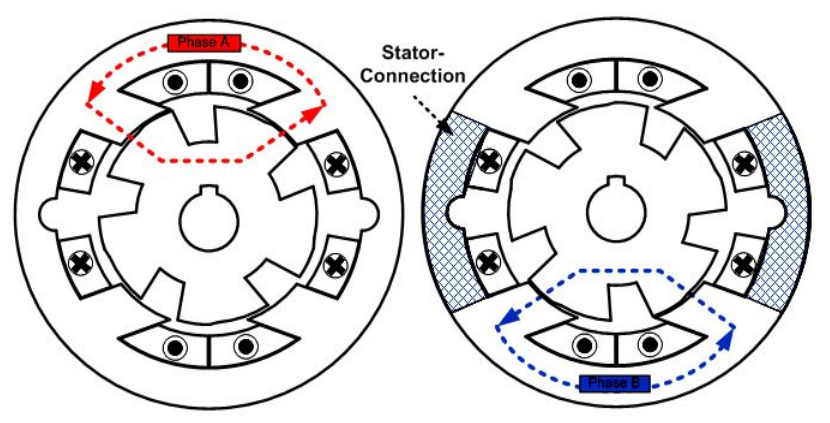

(a) Phase $\mathrm{A}$

(b) Phase B

Fig. 7. The magnetic flux paths of $4 / 5$ SRM

\section{Analysis of the double-stator SRM}

\subsection{Static analysis}

FEM is usually used for steady-state performance computations. The static analysis aims to analyze the different positions of the magnetic flux distribution between the stator and rotor. Fig. 8 shows the magnetic flux paths of the motor.

The flux distribution as shown in Fig. 8 demonstrates the switching sequence of the proposed motor with double stator. 'Zero degree' represents the initial position of motor rotation. At this position, the rotor is fully aligned with phase $\mathrm{A}$, while phase $\mathrm{C}$ is starting to overlap, and phase $\mathrm{B}$ is passing through the unaligned stator-rotor position. As one counter-clockwise revolution occurs, phase $\mathrm{A}, \mathrm{B}$, and $\mathrm{C}$ will be alternately excited.

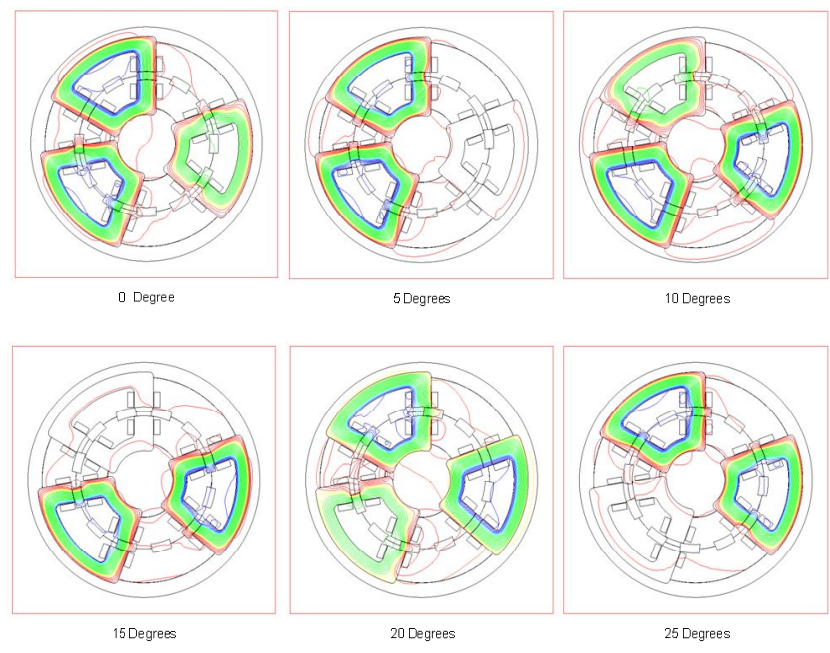

Fig. 8. Magnetic flux paths of double-stator SRM 


\subsection{Dynamic Analysis}

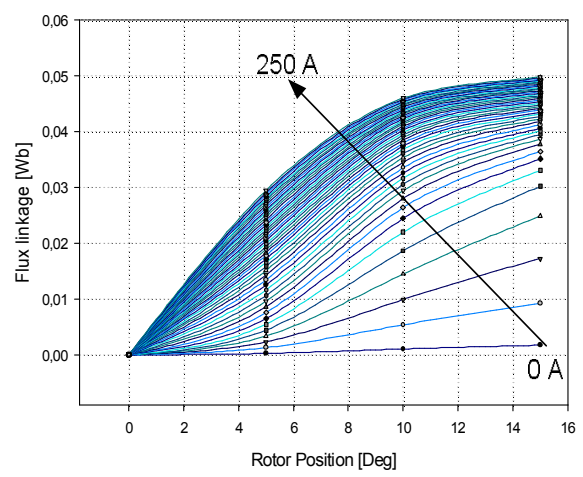

Fig. 9. Flux linkage of double-stator SRM

The SRM is characterized by its flux linkage, which varies with rotor position and current. The position-dependent behavior is due to the geometry of the overlapping stator and rotor teeth. In most SRM applications, saturation occurs and results in nonlinear inductances. This nonlinear behavior explains the difficulty in modeling and controlling the SRM. The variation of flux linkage with respect to the current for different rotor positions of the proposed motor is shown in Fig. 9.

The inductance profile of the SRM is dependent on the rotor position, due to its double-salient poles configuration. The relationship between inductance and rotor position for different excited currents of the double-stator SRM is shown in Fig. 10. The figure clearly presents the two distinct effects of saturation. When the rotor is near the aligned position, the flux is higher and the bulk effect begins. The magnetic saturation is responsible for the decrease of the inductance as the phase current increases. This is clearer when a rotor pole approaches the stator pole. The saturation effect is maximum at the aligned position, in which stator and rotor poles are perfectly aligned. At the unaligned position, where the two rotor poles are at the same distance from a stator pole, there is no magnetic saturation. The unaligned position curve is straight because of a large air gap in this position. In the unaligned position, the phase inductance is at its minimum. The saturation of the unaligned curve is less sharp due to the larger leakage flux in this position. The proposed motor employs four air gaps for one cycle of the magnetic flux.

The motor is designed to produce $117 \mathrm{Nm}$ as the maximum output torque. One-phase torque of the double-stator SRM travels through 30 mechanical degrees. The torque characteristic of the double-stator SR motor is shown in Fig. 11. The maximum torque production of the proposed motor with $250 \mathrm{~A}$ excited

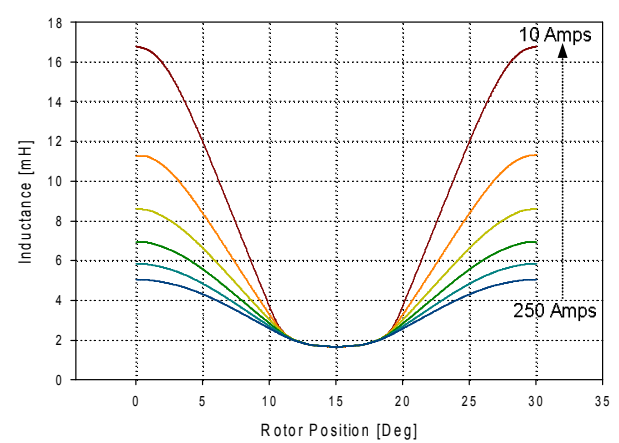

Fig. 10. Inductance of double-stator SRM

current is $130 \mathrm{Nm}$. This excessive torque production is due to the higher excited current. A $117 \mathrm{Nm}$ torque can be achieved with 230 A excitation current.

\section{Analysis of the $6 / 5 \mathrm{SRM}$}

\subsection{Static analysis}

The analysis of the three-phase 6/5 SRM with short flux path is based on the MAXWELL-2D software. The static analysis aims to analyze the magnetic flux distribution between the stator and rotor. The FEM analysis demonstrates that the flux flows only through the pole which is excited when the corresponding phase current is excited, and no flux flows through the other poles, which are not excited. Fig. 12 shows the flux distribution at both the aligned and un-aligned rotor positions of the 6/5 three-phase SRM.

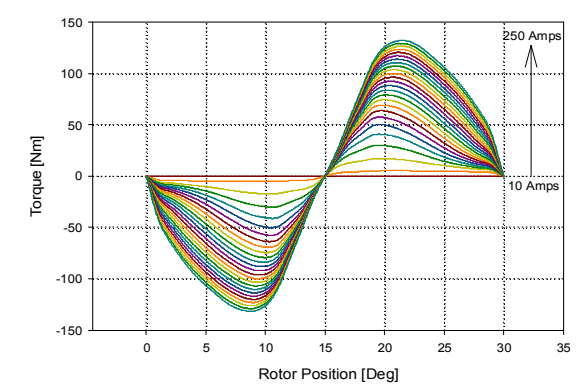

Fig. 11. Torque of the double-stator SRM

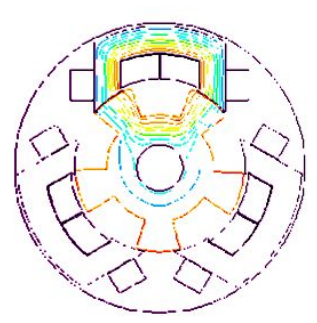

(a)

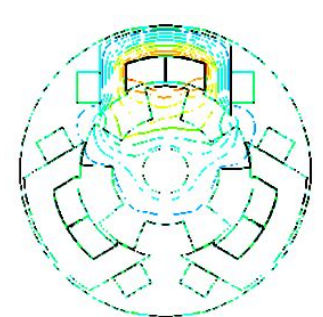

(b)
Fig. 12. Flux distribution of $6 / 5$ SRM (a) aligned, (b) unaligned 


\subsection{Dynamic Analysis}

The dynamic analysis of the three-phase 6/5 SRM with short flux path is targeted primarily at the torque, flux linkage and inductance of the motor. Torque is an important parameter to measure the motor performance. The torque of the SRM is produced by the unilateral magnetic force when the rotor poles are attracted to align with the excited stator phase, and the torque is independent of the polarity of the phase current. When a stator phase is energized, the nearest rotor pole is attracted toward the energized stator to minimize the reluctance of the magnetic path. In this condition, positive torque is produced.

Fig. 13 shows the torque versus rotor position for various excited currents of the $6 / 5$ three-phase SRM. From Fig. 13, it can be seen that the maximum torque values appear around the rotor positions of 20 degrees and 50 degrees.

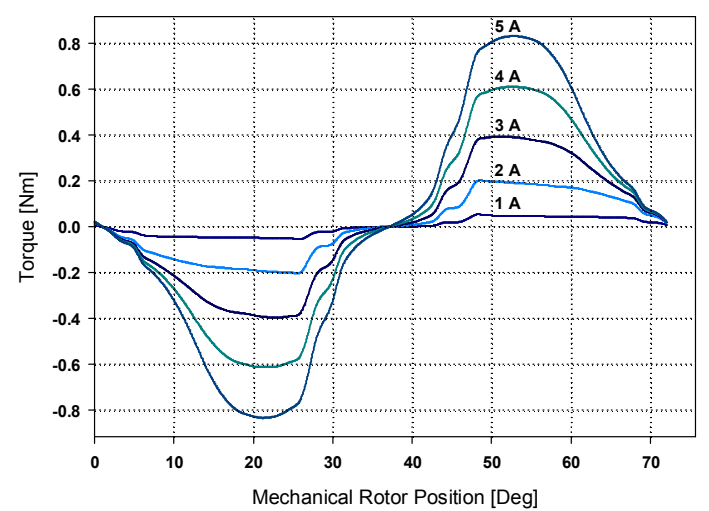

Fig. 13. Torque characteristics of $6 / 5$ SRM

Because of the special structure of the 6/5 SRM with short flux path and five rotor poles, the flux linkage characteristics rom the alignment position to the un-alignment position in one electrical cycle are much easier to obtain compared with those of the long-flux-path SRM, which are usually complicated by the nonlinear inductance and flux linkage. The initial rotor position of the motor is the fully-aligned condition and the rotor rotates in the counterclockwise direction. When the motor is in the aligned position $\left(0^{\circ}\right.$ and $\left.72^{\circ}\right)$, the flux is higher and the magnetic reluctance is at its lowest. At $36^{\circ}$, or the un-aligned stator-rotor position, the flux is lower due to an increase in phase reluctance. In the proposed motor, two adjacent teeth must coincide with two successive rotor poles in order to stream the magnetic flux through a shorter path. In that way, the maximum or optimal flux linkage can be achieved.

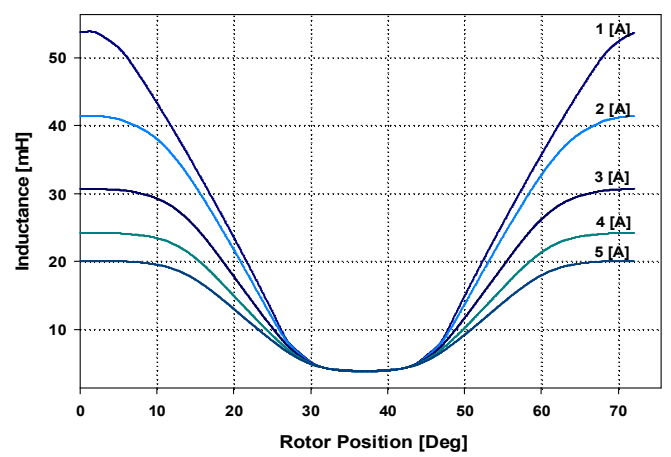

Fig. 14. Inductance characteristics of the $6 / 5$ SRM

The inductance is an important parameter of the motor, it has considerable effect on the torque generation, and can even affect the motor operation. The meaningful inductances of the SRM are obtained in the special positions: the maximum inductance is obtained when the rotor is in the aligned position, while the minimum inductance is obtained when the rotor is in the unaligned position. The phase inductance decreases gradually as the rotor poles go from the aligned position to the unaligned position. When the rotor poles are symmetrically misaligned with the stator poles of a phase, the position is said to be the unaligned position, and the inductance is minimum. The inductance curve with respect to the rotor position is shown in Fig. 14.

\section{Analysis of the $4 / 5$ SRM}

\subsection{Static analysis}

The flux distribution directly influences the performance and characteristics of the motor, so the flux should be set up as quickly as possible. The novel idea of short flux path shortens the magnetic flux path and forms the closed magnetic circuit rapidly. This "fast" flux distribution of the proposed motor is shown in Fig. 15.

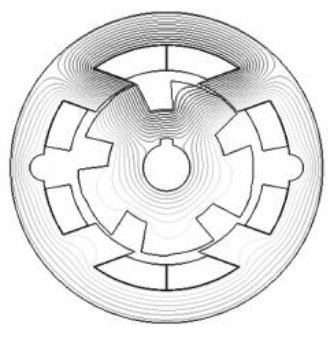

(a)

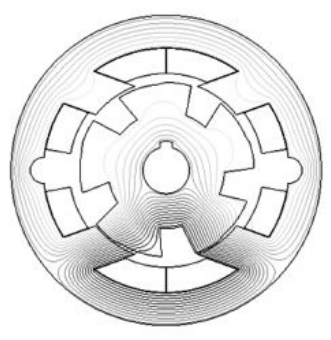

(b)
Fig. 15. Flux distribution of $4 / 5$ SRM (a) Phase A, (b) Phase B 


\subsection{Dynamic analysis}

The torque production of a SRM depends on the rotor position and the current. The torque generated by the SRM is nonlinear with the excited current. The proposed motor employs an asymmetric air gap. The torque in this structure is not symmetric. Fig. 16 shows the torque profile of the $4 / 5 \mathrm{SRM}$. It can be seen that the peak of the torque can be obtained around $20^{\circ}$ and $50^{\circ}$.

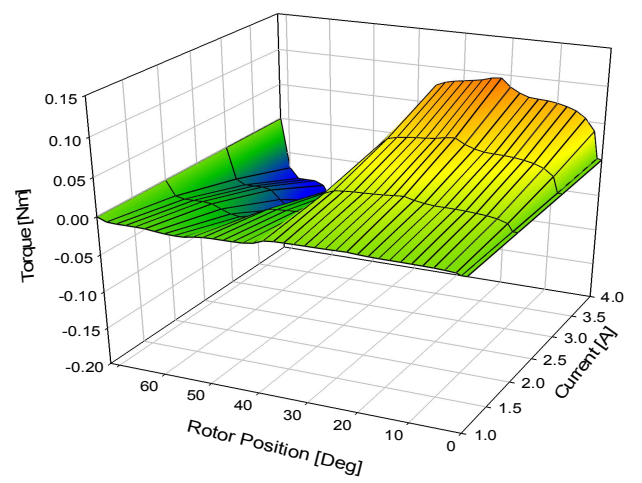

Fig. 16. Torque profile of $4 / 5$ SRM

The torque $T_{p h}$, with $i_{p h}$ is as the phase current and $L_{p h}$ as the inductance of the phase, can be expressed as:

$$
T_{p h}(\theta, i)=\frac{1}{2} i_{p h}{ }^{2} \frac{d L_{p h}(\theta)}{d \theta}
$$

where $\theta$ is the rotor position.

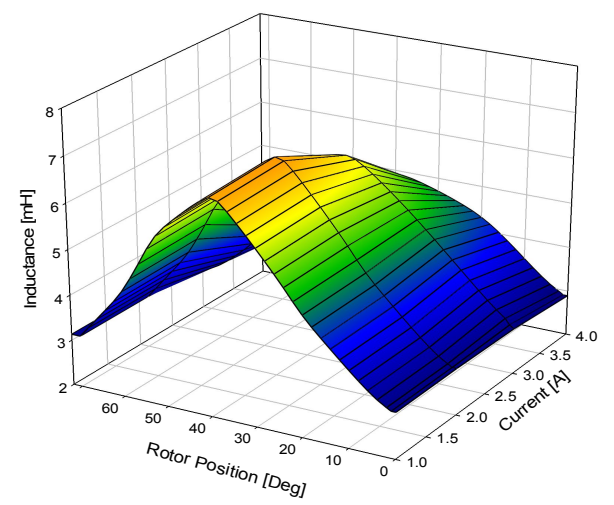

Fig. 17. Inductance profile of $4 / 5$ two-phase SRM

The torque production is proportional to the inductance variation with respect to the rotor position, and the square of the phase current of the motor. The slope of the inductance of the proposed motor is non-linear up to the normal commutation angle. This is due to the non-uniform air gap at the rotor surface. The magnitude of the increasing inductance slope $\left(0^{0}\right.$ to $\left.36^{\circ}\right)$ is smaller than the magnitude of the decreasing slope $\left(36^{0}\right.$ to $\left.72^{\circ}\right)$. This characteristic means that the maximum inductance shifts slightly from the origin to a higher angle of rotor position. This shifted inductance is related to the asymmetric torque production of the proposed motor. The inductance characteristic of the $4 / 5$ SRM is shown in Fig. 17.

\section{Comparison between short flux path and the conventional SRM}

\subsection{Short flux path of double-stator SRM}

A comparison between the conventional and the proposed structure is done in order to compare their performances. The results of the analysis indicate that the proposed geometry offers higher output torque compared with that of the general structure.

This comparison was done by using the same parameters and the same exciting current (230A) for both motors. Comparison between the conventional structure and the proposed structure with respect to the maximum output torque is shown in Fig. 18. The proposed SRM can meet the required maximum torque with excited current of $230 \mathrm{~A}$.

\subsection{Short flux path of $6 / 5 \mathrm{SRM}$}

A comparison between the C-core SRM with short flux path and conventional motors $(6 / 4,12 / 8$ and $6 / 8)$ is executed to compare the torque performance. The most important advantage of the $6 / 5$ SRM with short flux path is torque production, which is much larger than that of conventional motors. The four comparison models have the same motor dimensions. All the comparisons are done only through simulation. The comparison between the $6 / 5$ three-phase and the conventional motors is shown in Fig. 19.

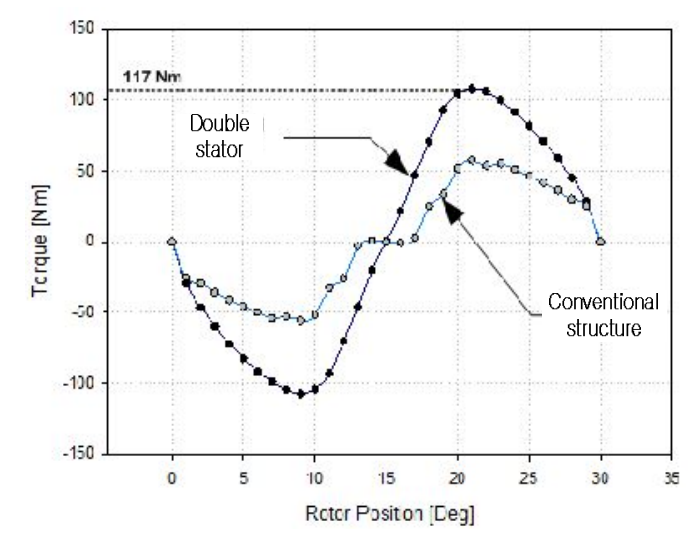

Fig. 18. Comparison of torque 


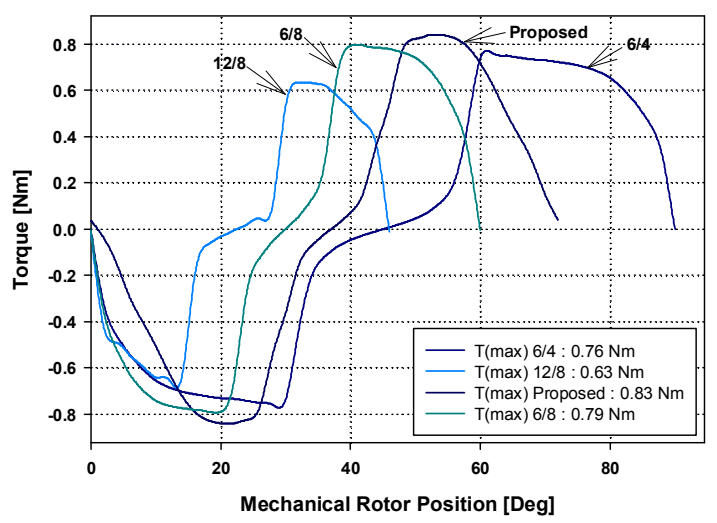

Fig. 19. Torque comparison of $6 / 5$ and conventional SRMs

The comparison shown in Fig. 19 shows that the three-phase 6/5 SRM with short flux path has the highest maximum output torque $(0.83 \mathrm{Nm})$ compared with other motors. That is an $8 \%$ improvement over the $6 / 4$ SRM with the same dimensions, which can generate a torque of $0.76 \mathrm{Nm}$.

\subsection{Short flux path of $4 / 5 \mathrm{SRM}$}

The 4/5 SRM employs a non-uniform air gap at the rotor pole surfaces. This condition makes the positive torque region wider, and the negative torque region narrower. The comparison between the proposed and conventional SRMs $(4 / 2,12 / 8)$ is executed. The comparison uses the same motor input parameters and dimensions for all motors. In order to keep the current densities as close as possible to one another, the numbers of turns in the windings are different for all of the motors. Also, different turn numbers are used in order to have the same magneto-motive forces.

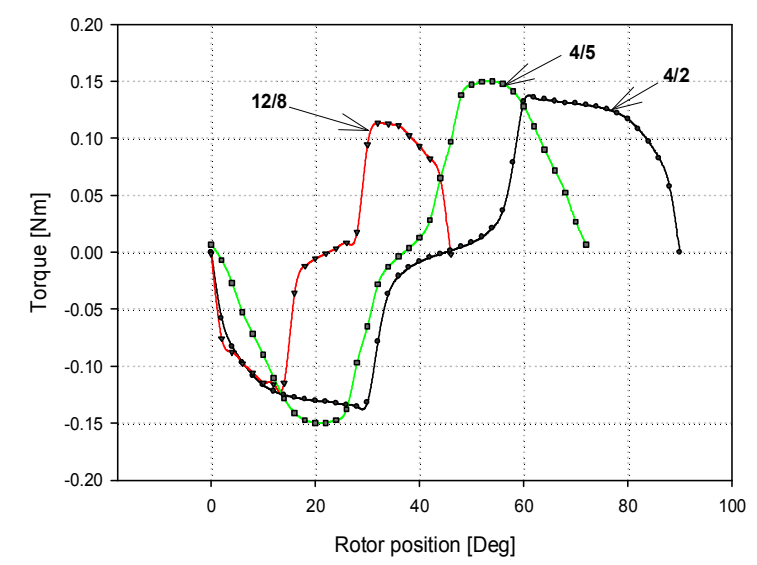

Fig. 20. Comparison between $4 / 5$ and conventional SRMs
It can be seen from Fig. 20 that the two-phase 4/5 SRM produces $15 \%$ higher torque than does the $4 / 2$ SRM. The number of rotor poles is related to the switching frequency of the SR drive. For high rotor pole numbers, such as $12 / 8$, the switching frequency is higher, but the torque interval is smaller. It can be seen that the $12 / 8$ SRM needs four times as much switching as the $4 / 5$ SRM.

\section{Conclusions}

A novel switched reluctance motor with short flux path is proposed. On the basis of the special structure, a double stator SRM, a three-phase 6/5 SRM with C-core, and a two-phase SRM with short flux path are designed and analyzed. The comparison between the proposed short-flux-path SRMs and various other motor structures demonstrates that the short-flux-path motor offers better performance.

\section{Acknowledgement}

This research was supported by Kyungsung University Research Grant in 2012.

\section{References}

[1] Krishnan R.: Switched Reluctance Motor Drives. CRC Press LLC, Boca Raton, Florida, 2001.

[2] Mohammadali Abbasian, Mehdi Moallem and Babak Fahimi, "Double-Stator Switched Reluctance Machines (DSSRM): Fundamentals and Magnetic Force Analysis," IEEE Transactions on Energy Conversion, vol. 25, no. 3, pp. 589 - 597, Sep. 2010.

[3] Jin-Woo Ahn, Dong-Hee Lee, Marully Tanujaya, "6/5 C-Core Type SRM", Korea Patent-2011-0081070.

[4] Jin-Woo Ahn, Dong-Hee Lee, Marully Tanujaya, "4/5 Two Phase SRM", Korea Patent-2011-0081068.

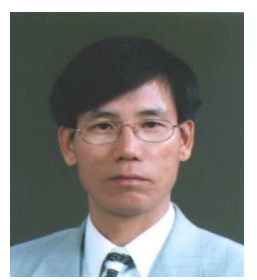

Jin-Woo Ahn was born in Busan, Korea, in 1958. He received his B.S., M.S., and Ph.D. degrees in Electrical Engineering from Pusan National University, Busan, Korea, in 1984, 1986 and 1992, respectively.

$\mathrm{He}$ has been with Kyungsung University, Busan, Korea, as a professor in the Department of Mechatronics Engineering since 1992. He was a visiting researcher in the Speed Lab at Glasgow University, U.K., a visiting professor in the Dept. of ECE and WEMPEC at the University of Wisconsin-Madison, USA, and a visiting professor in the Dept. of ECE at Virginia Tech from July 
2006 to June 2007. He was the director of the Advance Electric Machinery and Power Electronics Center. He was also the director of the Smart Mechatronics Advanced Research and Training Center from Aug. 2008 to July 2011, and has been the Senior Easy Life Regional Innovation System since July 2008 and president of Korea Regional Innovation System Association since December 2011 which are authorized by the Ministry of Knowledge Economy, Korea. He is the author of five books including SRM, the author of more than 150 papers and holds more than 25 patents. His current research interests are advanced motor drive systems and electric vehicle drives. He is Editor-in-Chief of JICEMS and associate editor of Journal of Electrical Engineering \& Technology. Dr. Ahn has received several awards including the Best Paper Award from the Korean Institute of Electrical Engineers in 2002 and 2011 The Korean Federation of Science and Technology Society in 2003, Korean Institute of Power Electronics in 2007, Park Min-Ho Prize in 2009, Busan Science \& Technology Prize and Ministerial Citation, Ministry of Knowledge Economy, Korea, in 2011, respectively. He is a fellow member of the Korean Institute of Electrical Engineers, a member of the Korean Institute of Power Electronics and a senior member of the IEEE. 